\section{ESTÁDIO DO MARACANÃ: UM ESTUDO COMPARATIVO ENTRE AS REPRESENTAÇÕES SOCIAIS DOS TORCEDORES SOBRE O ANTIGO E $O$ NOVO LUGAR DO FUTEBOL}

\author{
THE MARACANÃ STADIUM: A COMPARATIVE STUDY BETWEEN FANS' \\ SOCIAL REPRESENTATIONS ABOUT FOOTBALL'S OLD AND NEW PLACE
}

ESTADIO DEL MARACANÃ: UN ESTUDIO COMPARATIVA ENTRE LAS REPRESENTACIONES SOCIALES DE LOS INCHAS SOBRE EL ANTIGUO Y EL NUOVO SITIO DEL FÚTBOL

\section{Ana Beatriz Correia de Oliveira Tavares*, Silvio de Cassio Costa Telles**, Sebastião Josué Votre ${ }^{\star \star *}$}

Palavras chave

Futebol.

Percepção.

Espaço.

Keywords:

Soccer.

Perception.

Space.

Palabras clave:

Fútbol.

Percepción.

Espacio.
Resumo: 0 objetivo deste estudo foi comparar as representações sociais de torcedores sobre o estádio do Maracanã antes e após a reforma de 2010. A metodologia utilizada foi da análise prototípica. Percebemos que a estrutura do núcleo central e o sistema periférico sofreram algumas alterações em sua composição em função do novo espaço do futebol, que impôs novas práticas e comportamentos ao torcedor.

Abstract: Using prototypical analysis, this study compares football fans' social representations about the Maracanã stadium before and after its 2010 remodeling. It found that the structures of the core and the peripheral system have undergone some changes in their composition due to the new space occupied by football, which imposed new practices and behaviors to fans.

Resumen: El objetivo de este estudio fue comparar las representaciones sociales de los aficionados del estadio Maracanã antes y después de la reforma de 2010. La metodología utilizada fue el análisis prototípica. Damonos cuenta de que la estructura del núcleo y del sistema periférico han sido objeto de algunos cambios en su composición debido al nuevo espacio del fútbol, que imponía nuevas prácticas y comportamientos para los aficionados.
*Instituto Federal de Educação, Ciência e Tecnologia do Rio de Janeiro. Rio de Janeiro, RJ, Brasil.

E-mail: ana.tavares@ifrj.edu.br

**Universidade Federal do Rio de Janeiro.Rio de Janeiro, RJ, Brasil. E-mail: silviotelles@ifrj.br

***Unisuam. Centro universitário Augusto Mota. Rio de Janeiro, RJ, Brasil.

Recebido em: 15-08-2017 Aprovado em: 08-03-2018

DOI:

http://dx.doi.org/10.22456/1982-8918.75681

(c) (1) ()ㅡㄴ Licence 


\section{INTRODUÇÃOO}

Estudar o estádio do Maracanã ao longo de sua história é se deparar com mudanças estruturais visíveis, tanto no seu interior/exterior quanto no seu entorno. 0 estádio, que em 1950 foi inaugurado ainda inacabado, passou em 2010 por uma reestruturação arquitetônica praticamente completa, em que foi mantida apenas sua fachada externa.

Essas mudanças não atingiram apenas o estádio do Maracanã, mas também todos os estádios que almejavam receber jogos internacionais e que, por isso, deveriam seguir as normatizações da Federação Internacional de Futebol (FIFA). Tais normatizações visam, dentre outros aspectos, garantir a segurança dos torcedores. Segundo Mascarenhas (2013, p. 147), os "superestádios, localizados nas grandes capitais, vêm sendo alvo de intensas transformações, físicas e normativas, num processo cuja radicalidadeafeta o próprio campo lexical do futebol: passam a se chamar arenas".

As novas arenas chegam com propostas diversificadas, atentas não apenas aos tradicionais jogos de futebol, mas também à realização de shows, musicais, eventos, entretenimentos de uma maneira geral. As transformações ultrapassaram a questão da segurança. Os novos estádios/arenas também devemoferecer conforto,além de serem construções sustentáveis, trazendo benefícios tanto ambientais quanto econômicos, não só para os que vivenciam o estádio, mas para acomunidade em geral (MELLO, 2013, p.156).

As dinâmicas de uso do espaço,assim comoa forma de torcer, também sofreram alterações, impondo um novo formatodesde a compra dos ingressos, passando pelo comportamento dos torcedores no interior do estádio até as formas de acessona entrada e saída de um jogo.

Especificamente no Maracanã, desde sua reabertura em 2013, a compra pela internet foi um modo novo de adquirir o ingresso. Entretanto, essa forma,embora tenha proporcionado algumas comodidades, também trouxedesconfortos, como, por exemplo, no setor de cadeiras numeradas,em que havia dificuldade na aquisição de assentos juntos quando eram comprados em momentos distintos. Além disso, apesar de a compra se dar pela internet, havia ainda a necessidade de passar por algum posto de troca para buscar o ingresso, o que fazia o torcedor perder tempo e até dinheiro em função do deslocamento.

Após o uso inicial do estádio, algumas dessas práticas foram sofrendo adaptações e hoje já é possível trocar os ingressos em guichês no próprio Maracanã, facilitando a ida ao jogo. Para os que compram no dia da partida (logo na reabertura não era possível essa prática), ainda há filas, como no antigo ${ }^{1}$ Maracanã. 0 sistema de lugares marcados que foi implantado na Copa do Mundo de 2014 não deu certo em jogos nacionais e alguns setores perderam essa característica, com torcedores inclusive permanecendo em pé, prática proibida no interior do estádio. Tais acontecimentos demonstraram a necessidade de uma fase de ajuste em relação às práticas e comportamentos adotados.

Sobre o antigo Maracanã, Tavares e Votre (2014), ao analisarem registros das memórias dos torcedores sobre o estádio, verificaram que os significados apontados mostram que foram sendo construídos ao longo do tempo a partir de diferentes cenários, que instituíam determinados comportamentos não encontrados atualmente. 
Como exemplo, havia as torcidas entrando juntas pela mesma rampa, torcedores sentados no concreto das arquibancadas, muitas vezes apinhados, circulação por todo anel externo e, também, pelas arquibancadas, para acompanhar o lado em que seu time atacava, entre outras dinâmicas que com o tempo foram auxiliando na construção das representações sobre o estádio. Práticas e comportamentos são ações socialmente construídas e categorias importantes nas discussões das representações sociais sobre um determinado objeto.

Segundo Rouquette (1998, p. 39),

[...] o que pensamos depende daquilo que fizemos (ou, mais exatamente, aquilo que se vem pensar depende daquilo que se fez, ou se foi levado a fazer anteriormente), e aquilo que fazemos em um dado momento, depende daquilo que pensamos então, ou daquilo que pensamos anteriormente.

A discussão entre prática e representação se desmembra em três possibilidades. A primeira ideia é quando a representação determina as práticas. A segunda, ao contrário, as práticas determinam as representações. Essa concepção é entendida como mais radical, pois entende que somente condições objetivas determinariam as representações, desconsiderando as interferências das normas e valores culturais. Já a terceira ideia seria a da reciprocidade entre prática e representação, concepção hoje predominante por acreditar-se no "[...] caráter dialético dessa relação, na qual cada um dos pólos constitui uma totalidade indivisível, atuando, ambos, como um sistema que gera, justifica e legitima o outro" (ALMEIDA; SANTOS; TRINDADE, 2000).

A atual configuração do Maracanã abre caminho para pesquisarmos sobre a relação entre prática e representação e a alteração dessa relação a partir de uma reestruturação no estádio. Tal análise nos permite verificar a importância que um espaço esportivo tem para um determinado grupo e a interferência que as alterações arquitetônicas e o estabelecimento de novas práticas podem acarretar para os indivíduos.

Postulamos em nosso estudo que astransformações arquitetônicas realizadas no Maracanã, determinantes de novas práticas/comportamentos para os torcedores, acarretam alteração nas representações sociais sobre o estádio. Buscamos identificar neste estudo a estrutura dessas novas representações sociais dos torcedores sobre o novo Maracanã comparando-as com as representações sobre o antigo estádio.

\section{DECISÕES METODOLÓGICAS}

Nosso estudo caracteriza-se como quali-quantitativo, em virtude da utilização de quadros que trabalham com cálculos de frequências e ordem de evocações de palavras associados ao caráter interpretativo das categorias elencadas. Seguimos o referencial teórico das Representações Sociais a partir da abordagem estrutural, também conhecida como Teoria do Núcleo Central. Tal abordagem, proposta por Abric (1998), é uma das escolas existentes sobre representações sociais, que as concebe como estruturas de conhecimento sobre os fatos sociais compartilhados por grupos. Para o autor, as representações sobre um objeto se organizam em torno de um núcleo central, mais rígido, menos suscetível a mudanças, e que tem como função assegurar a permanência das representações. As representações apresentam ainda um sistema periférico, associado ao contexto de vida imediato, mais instável e suscetível a mudanças e que tem como função proteger o núcleo central. 
Segundo Abric, para estudarmos uma alteração da representação temos que conhecer o núcleo central, pois só poderemos assegurar se houve alguma mudança nas representações de um grupo sobre um determinado objeto se elas se organizarem em torno de dois ou mais núcleos diferentes. Portanto, em um estudo comparativo entre duas representações, necessitamos realizar o levantamento de seus núcleos centrais.

Para este estudo utilizamos a técnica das evocações livres ou análise prototípica (OLIVEIRA et al., 2005), proposta por Vèrges² ${ }^{2}$ largamente utilizada nos estudos da abordagem estrutural em que se pretende identificar a estrutura das representações sociais.

A técnica propõe que através de um termo indutor o informante associe, livre e rapidamente, outras palavras. Os termos evocados são tratados considerando a frequência (F) com que aparecem e a ordem média de evocações (OME). A OME diz respeito à ordem em que o termo foi evocado. A partir do cruzamento dessas duas coordenadas se organiza um quadro de quatro casas ou quadrantes, em que se estabelecem no quadrante superior esquerdo os termos do núcleo central (são os termos com uma alta frequência de evocação e uma baixa OME, ou seja, os mais rapidamente evocados). O quadrante inferior esquerdo é chamado zona de contraste (são termos com baixa frequência, mas prontamente evocados), podendo demonstrar uma centralidade das representações para um subgrupo. Já osquadrantes superior e inferior direito são denominados primeira e segunda periferia (comportam os termos tardiamente evocados com alta ou baixa frequência). Entende-se que os termos evocados prontamente e com uma maior frequência entre os informantes são os que circulam no grupo estudado constituindo as representações mais centrais.

Realizamos a coleta de dados em dois momentos distintos. O primeiro momento foi em 2012, período em que o Maracanã estava fechado para ser reformado para a Copa do Mundo de 2014. O estudo contou com a participação de 40 informantes (dez torcedores de cada um dos quatro times mais representativos do futebol carioca - Flamengo, Fluminense, Vasco e Botafogo). Essa etapa foi realizada em jogos do Campeonato Carioca no estádio Engenhão e nas sedes das torcidas organizadas dos quatro clubes.

Como critério de inclusão, os informantes, de qualquer gênero, tinham que ter freqüentado o estádio, no mínimo, por 15 anos, e ter vivenciado o Maracanã na sua configuração original. Foi solicitado que eles falassem quatro palavras que associavam ao termo indutor "Estádio do Maracanã". A amostra contou com 160 evocações. Após a tabulação e análise dos dados daquele momento, constatamos que a quarta palavra era pouco produtiva, e não afetava o núcleo central das representações. Demorava para ser enunciada, por vezes não aparecia, ou vinha após falso começo, recomeço ou hesitação. Por esta razão, estabelecemos que em próximos estudos trabalharíamos com três palavras evocadas.

O segundo momento foi realizado em 2015, após a reabertura do estádio, simbolicamente denominado'novo' Maracanã. O estudo agora contou com 96 novos informantes (24 torcedores, sem atenção para gênero, de cada um dos quatro times da primeira etapa). A coleta se deu nos jogos do CampeonatoBrasileiro, realizados no próprio Maracanã. Como critério de inclusão esses informantes deveriam ter frequentado o antigo estádio desde 1995 (portanto durante 15 anos) e o novo (desde 2013). Foi solicitado que eles falassem as três primeiras palavras que associavam ao termo indutor "Estádio do Maracanã". A amostra contou com 288 evocações. 
Conforme enunciamos acima, nesse segundo momento entendemos quetrês palavras seriam satisfatórias para o nosso estudo ${ }^{3}$. Segundo Wachelke e Wolter (2011, p. 522),

As pesquisas que empregam análises prototípicas tipicamente solicitam de três a cinco respostas por participante, mas a princípio a técnica poderia ser empregada também com número de respostas diferente, e mesmo sem restrições de quantidade.

Nos dois momentos, trabalhamos com informantes pertencentes ou não a torcidas organizadas, que frequentassem o estádio do Maracanã no mínimo uma vez por mês. Quanto aos15 anos estipulados, justifica-se esta delimitação pelo fato de esses torcedores terem conhecido o estádio antes das reformas estruturais que ocorreram a partir do ano de 2000, 0 que nos permitiu estabelecermos parâmetros comparativos.

Nos dois estudos utilizamos como critério de corte para o quadro de quatro casas a média, tanto em relação à frequência quanto em relação à ordem média de evocação. No primeiro estudo o ponto de corte foi de 9,4 para a frequência e de 2,50para a OME. No segundo, sobre o novo Maracanã, o ponto de corte foi de 18,5 para a frequência e de 2,03 para a OME. Desconsideramos nos dois estudos os termos com frequência igual a 1 (hápax). Utilizamos 0 critério do conteúdo para categorizar os termos. Esse é um dos critérios da técnica, em que se agrupam palavras com significados semelhantes em relação ao conteúdo, como, por exemplo, "casa" e "lar" ou "espetacular" e "brilhante", considerando-as como pertencentes às mesmas categorias.

Os dois quadros produzidospela técnica descrita acima nos permitiram verificar a estrutura da representação social dos torcedores sobre o antigo (Quadro 1) e sobre o novo (Quadro 2) estádio do Maracanã.

A técnica foi complementada por entrevistas semiestruturadas, realizadas nos dois momentos do estudo. Em 2012 os informantes que participaram da evocação foram os mesmos que responderam as entrevistas. Em 2015 uma nova amostra foi selecionada e os informantes pronunciaram as palavras solicitadase tambémresponderam as entrevistas.0 objetivo das entrevistas foi o de auxiliar na análise das categorias do núcleo central e dos elementos periféricos,verificadas no quadro de quatro casas.

As entrevistas continham três blocos disparadores, abordando os seguintes pontos: significados do estádio para os torcedores; as experiências vivenciadas no estádio pelos torcedores; e as memórias produzidas na vida dos torcedores.

Em 2015, por ser o Maracanã um espaço recém-inaugurado,com inúmeras alterações, tanto estruturais quanto na forma de uso pelos torcedores, achamos que os significados circulantes ainda não estariam sedimentados na memória dos informantes. Em função disso, optamos por ampliar o número da amostra,aumentando assim o número total de evocações. Segundo Wachelke e Wolter (2011, p.523), "[...] quanto mais numeroso o grupo de participantes, mais estáveis serão os resultados [...] aproximando-se da realidade observada".

Os dois estudos foram aprovados pelo comitê de ética sob os números: CAAE: 07820112.7.0000.5287 (2012) e CAAE: 35564314.9.0000.5259 (2014).

3 Nesta técnica da evocação a quantidade de termos solicitados ao informante não influi na análise do núcleo central, uma vez que inclusive o pesquisador pode solicitar cinco termos e o informante pronunciar apenas dois, por exemplo. Assim, a importância na análise é a repartição dos termos pronunciados pela amostra em relação a três pontos de corte: frequência mínima; frequência baixa versus alta; e ordem média de evocação alta versus baixa. 


\section{ANÁLISE DOS DADOS}

Como nosso objetivo foi verificar as mudanças nas representações seguindo a abordagem estrutural, a análise do núcleo central é a de maior importância. Conforme já descrito, devemos observar uma mudança na composição do núcleo central para constatarmos alterações nas representações de um grupo.

Os Quadros 1 e 2 mostram a estrutura das representações sociais de torcedores sobre o "antigo" e "novo" estádio do Maracanã.

Quadro 1 - Dados sobre a estrutura das representações em 2012

\begin{tabular}{|c|c|}
\hline ELEMENTOS CENTRAIS & PRIMEIRA PERIFERIA \\
\hline $\begin{array}{c}\text { EMOÇÕES ( } F=46 ; \text { OME }=2,44) \\
\text { TIME }(F=21, \text { OME }=2,33) \\
\text { FUTEBOL }(F=16 ; \text { OME= 2,44) } \\
\text { ESTÁDIOESPETACULAR }(F=16 ; \text { OME }=2,31) \\
\text { CASA }(F=9,0 ; \text { OME }=2,11)\end{array}$ & NOSTALGIA (F=14; OME= 2,71) \\
\hline ZONA DE CONTRASTE & SEGUNDA PERIFERIA \\
\hline $\begin{array}{c}\text { TíTULOS }(\mathrm{F}=8,0 ; \text { OME }=2,25) \text { LAZER }(\mathrm{F}=4,0 \text {; } \\
\text { OME=2,25)AMIZADE }(\mathrm{F}=3,0 ; \text { OME=2,0) }\end{array}$ & $\begin{array}{c}\text { FESTA }(\mathrm{F}=7,0 ; \text { OME=2,57)FANATISMO (F=2,0; } \\
\text { OME=4,0)MULHER ( } \mathrm{F}=2,0 ; \text { OME=4,0)CULTURA ( } \mathrm{F}= \\
2,0 ; \text { OME }=4,0)\end{array}$ \\
\hline
\end{tabular}

Fonte: dados da pesquisa

Quadro 2 - Dados sobre a estrutura das representações de 2015

\begin{tabular}{|c|c|}
\hline ELEMENTOS CENTRAIS & PRIMEIRA PERIFERIA \\
\hline MODERNO (F=40; OME=1,98) & \\
TIME (F=39;OME1,64) & TÍTULOS (F=19;0ME=2,65) \\
EMOÇÕES (F=33;OME2,03) & \\
ESTÁDIO ESPETACULAR (F=24;OME=1,92) & \\
NOSTALGIA (F=24;OME=1,88) & SEGUNDA PERIFERIA \\
RUIM (F=22;OME=1,77) & FESTA (F=13;OME=2,38) \\
\hline ZONA DE CONTRASTE & ELITISTA (F=11;OME=2,18) \\
\hline GRANDE (F=9; OME=1,89) & AMIZADE (F=8;OME=2,13) \\
TEMPLO ( $F=7 ;$ OME=1,43) & TORCIDA (F=4;OME=2,75) \\
\hline FUTEBOL $(F=6 ; O M E=2,0)$ & \\
\hline
\end{tabular}

Fonte: dados da pesquisa

Analisando o Quadro 1, identificamos que o núcleo central referente ao antigo Maracanã está fortemente associado às emoçõesexperimentadas pelos torcedores naquele espaço durante os anos em que acompanharamos jogos de seus times. Sentimentos como amor, paixão, alegria, tristeza, raiva eram vivenciados no estádio.

Analisando as entrevistas com atenção flutuante e foco na lista de evocações acima, encontramos evidências de que as falas dos torcedores confirmam o quadro das representações. Em vista disso, optamos por editar, sintetizar e amalgamar parte das falas, relacionadas às evocações, como manifestações do discurso do sujeito coletivo, nos termos de Votre, Alves e Melillo (2010), não se configurando como falas individuais. A edição que se segue ilustra como torcedores lidavam com a emoção: 
Entrar no Maracanã e ver aquele estádio cheio, como uma cor, uma vibração, era muito lindo ver a emoção das pessoas; assim que chegava sempre era uma alegria e o nervosismo; muito tenso sempre, e quando o time ganhava de extrema êxtase e alegria, quando perdia, depressão; alegria, euforia, angústia, alívio, tristeza, decepção e raiva; a gente vai do limite máximo do prazer ao fundo do poço.

Experiências marcantes facilitam a construção de lugares afetivos, através das vivências de cada partida dentro do estádio onde, segundo Tuan (1983), os indivíduos são afastados das distrações externas, os sentimentos comuns são estabelecidos e consolidados, exercendo forte impacto sobre esses indivíduos.

Com suporte nas entrevistas realizadas, podemos analisar que tais sentimentos relacionados ao estádio possivelmente se misturam com a paixão pelos times de futebol por qual torcem os informantes. Praticamente a metade dos informantes associaram 0 estádio ao time (Flamengo, Fluminense, Vasco e Botafogo), demonstrando uma simbiose, afinal, na maioria dos casos, o que leva os torcedores ao Maracanã é o jogo de futebol do seu time, a exemplo do depoimento seguinte: "O maior lazer pra mim é assistir o Flamengo, então todo final de semana eu estava no Maracanã; Maraca é FlaxFlu".

O futebol é o esporte que proporciona a constituição desse espaço e não é à toa que aparece no núcleo central. Está diretamente associado a um dos principais palcos do esporte no Brasil. A Copa do Mundo de 1950, evento responsável pela construção do estádio, assim como Pan-Americano, Mundial de Clubes, Campeonato Brasileiro e Carioca utilizam esse espaço como o cenário para o futebol brasileiro.

Os outros dois termos que compõem o núcleo central (estádio espetacular e casa) se deslocam do indivíduo e do esporte para fazer associações diretamente com o espaço. Os adjetivos verbalizados pelos informantes demonstram o fascínio exercido pelo Maracanã e 0 quanto o estádio é visto como fantástico, brilhante, o melhor, o mais charmoso, bonito e o maior de todos. É um espaço representativo dos cariocas e da cidade, acessível aos olhos de todos que passam no entorno e que mesmo após 60 anos e com problemas estruturais, o que circula como núcleo central é a monumentalidade da construção. É o que se verifica na edição seguinte:

\begin{abstract}
Maracanã é diferente de tudo; vê aquele estádio imenso; sentia que eu tava entrando numa dimensão diferente; Maracanã é muito maior, muito mais gente, o clima é outro; Maracanã é incomparável pela grandeza, pela história; Maracanã tem uma magia diferente, a localidade, o espaço, a beleza, o campo; coisa linda, maravilhosa, o Maracanã foi uma das cosas mais bonitas que existia aqui no Rio de Janeiro, uma coisa fantástica!
\end{abstract}

Esse estádio monumental vivenciado por todos esses anos acaba fazendo parte da história de cada um dos torcedores, se transforma na extensão da própria casa, um templo sagrado. Nesse espaço muito dos informantes experimentam diversos sentimentos a cada jogo, fazem amizades, usufruem de um lazer que os retira do cotidiano, das atividades corriqueiras. É nessa casa que eles tecem suas redes de sociabilidade e constroem sua identidade de torcedores, como sujeito coletivo:

Maracanã é como se fosse a nossa casa; aquilo lá é meu templo; um sentimento de pertencimento; relação de familiaridade que eu tinha com o Maracanã;ir ao Maracanã, eu faço desde que eu tinha 15 anos, então há mais de vinte anos que eu faço isso, então é quase que uma relação de amizade, de família, que a gente tem com o Maracanã. 
Ser representado como casa demonstra o aconchego desse espaço, a afinidade que se construiu proporcionada pelo passar dos anos. São idas e vindas nos finais de semana, são experiências acumuladas a cada jogo, são sentimentos vividos que vão da alegria à tristeza, da derrota à vitória. Um espaço desconhecido se torna lugar quando, a partir das experiências vividas, do transcurso do tempo e da intensidade das emoções, os indivíduos desenvolvem uma afeição por ele (TUAN, 1983). E o Maracanã se tornou essa casa para os torcedores, esse lugar que marca sua vida, que traz na lembrança momentos importantes.

No quadro, a zona de contraste apresenta termos interessantes que se mostram representativos para um subgrupo uma vez que foram prontamente evocados. Termos como lazer, amizade e lembranças mostram a importância desse espaço para a sociabilidade dos indivíduos.

Na primeira periferia identificamos o termo "nostalgia". Esse termo possivelmente aparece porque os jogos, no período da coleta dos dados, estavam sendo realizados em outros estádios, logo, ao serem questionados, os torcedores demonstraram saudade dos jogos realizados no Maracanã. Essa zona do quadro deve ser analisada entendendo que ela está muito próxima do núcleo central. São termos que circulam ao redor dos elementos centrais preservando esse núcleo duro. Além de demonstrarem saudosismo pelos jogos naquele espaço, também relembram jogadas e jogadores que marcaram a vivência no espaço e de alguma forma também simbolizam o estádio.

\begin{abstract}
Medo de perder; acabaram com a nossa casa; espero que ele não perca aquela magia de antes. A gente sente muita falta do Maracanã; tá sempre na minha memória e tá sempre na minha lembrança;agora vai fazer falta o cimento, 0 concreto que a gente estava acostumado a ficar sentado, ficar em pé;dá uma nostalgia, dá uma tristeza;olha, sinceramente, nunca o Maracanã vai ser aquilo que foi;perdemos o Maracanã; tiraram o Maracanã do povo.
\end{abstract}

Por fim, o quadrante correspondente à segunda periferia, em que aparecem os elementos menos frequentes e mais tardiamente evocados (festa, fanatismo, mulher e cultura), representa também os elementos periféricos, mais flexíveis e suscetíveis às mudanças e para nosso estudo comparativo das possíveis alterações no núcleo central são os que têm uma importância menor.

Durante a entrevista, ficava claro que a presença feminina representava mais um apelo para os torcedores, que em um campo predominantemente masculino viam mais uma oportunidade de fazer valer sua condição de conquistadores. Percebemos que o termo "mulher", que aparece no primeiro quadro, mas desaparece no segundo, representa o universo machista, onde o estádio também era local de "azaração" e affair.

O fato de o termo ter desaparecido não aponta, em nosso estudo, que houve redução no número de mulheres que frequentam o Maracanã, mas que no quadrante em que o termo se encontrava, distante do núcleo central, as variações das evocações são mais voláteis. Cabe destacar que as transformações dentro dos estádios, trazendo mais conforto e segurança, proporcionaram um incremento no número de mulheres que passaram a frequentá-los. Bandeira (2017) aponta que a elitização proveniente do processo de modernização das arenas tornou a presença das mulheres uma constante e que tal alteração representou um investimento para que isso de fato ocorresse.Apesar desse aumento, o autor ainda relata que, como o ambiente ainda é machista, os olhares e assédios ainda são constantes, mas que 
o crescimento do quantitativo de mulheres representa um grande passo para que haja uma mudança de mentalidade do espaço.

Três anos após a reabertura do estádio, em 2015, realizamos nova coleta de dados para verificar se a reestruturação arquitetônica, com as novas práticas e comportamentos, alterou as representações sociais sobre o Maracanã.

O Quadro 2 mostra como se configura o quatro de quatro casas e quais termos foram alterados de quadrante, mantidos, acrescentadas ou suprimidos pelos torcedores. Verificando o quadrante do núcleo central, observamos que alguns termos permaneceram sendo evocados pelos torcedores, demostrando que as alterações arquitetônicas não configuraram uma mudança radical do núcleo central.

Termos como "time", "emoções" e "estádio espetacular" permanecem sendo evocados prontamente e por um alto número de torcedores. Por mais que circule a ideia de que o Maracanã não é mais o mesmo, perdeu seu charme e não tem mais emoção,ela não é confirmada pelos torcedores que efetivamente voltaram a frequentar o novo estádio acompanhando seus times.

O estádio continua a ser associado aos times dos torcedores. Na maioria das vezes, 0 torcer pelo time é a mola propulsora para que eles vivenciem o estádio assistindo aos jogos de futebol, por isso a forte ligação entre o Maracanã e o time de coração. Assistir às partidas nesses três anos após a reabertura também continua possibilitando a vivência das emoções. Alegria, tristeza, raiva, amor, euforia, entre tantos outros sentimentos experimentados a cada jogo, continuam sendo vivenciados pelos torcedores. Também permanece sendo compartilhada a ideia de ser um estádio maravilhoso, bonito, espetacular e simbólico. É nesse espaço que eles vivenciam as emoções junto aos seus times.

Entretanto, ao lado desses adjetivos até então dominantes aparece uma nova categoria com termos evocados que só denigrem a imagem do Maracanã. Nessa categoria ruim, reunimos adjetivos negativos, como "feio", "péssimo", "mal-administrado", que acionam uma fala que vem desde a época da reforma quando existia uma incerteza sobre como ficaria o novo estádio. Possivelmente os torcedores suscitam tais termos como uma forma de protesto contra o novo, contra a perda de sua própria casa. "[...] está muito mal-administrado; uma bagunça; acabaram com a beleza do nosso estádio; está feio demais".

Esse sentimento de perda da casa nos remete para a categoria "nostalgia". Em 2012, 0 estádio fechado e as incertezas de como seria o novo cenário do futebol fizeram com que o termo aparecesse na primeira periferia, significando uma alta frequência embora tardiamente evocado. Em 2015 ele se altera indo compor o núcleo central. Agora reaberto não existe mais incertezas e para muitos 0 antigo Maracanã cedeu espaço definitivamente para a nova arena de futebol. As lembranças de momentos vivenciados, de práticas e comportamentos representativos de um domingo de jogo, talvez por não serem mais percebidos e experimentados, transferem para o campo da saudade o antigo Maracanã. Possivelmente tivemos uma indicação em 2013 que em 2015 se confirmou, o antigo Maracanã deu espaço para um novo estádio: "[...] Perdeu a imponência que tinha antes; é como a casa de um amigo reformada que você quase não reconhece; é um outro estádio".

De fato, o que aconteceu com o Maracanã já se configurava como uma tendência mundial. Segundo Gaffney e Mascarenhas (2004), posteriormente a uma sistemática expansão, em número e porte físico, os estádios em diversas partes do globo reduziram sua 
capacidade de público, buscando atender a uma nova ordem no oferecimento de serviços de melhor qualidade, caracterizando-se como recentes pontos positivos nesta nova fase do estádio. Outras mudanças apontadas pelos autores foi advento da receita proveniente das transmissões das partidas e a entrada de patrocínios que se tornaram determinantes para uma drástica mudança na economia do futebol. Essas transformações impactam não somente na estrutura dos estádios, mas também na conduta dos torcedores, que devem agora adequar-se a um novo padrão de conforto e segurança.

Agora os ingressos nos estádios deixaram de ser a principal fonte de rendimentos dos clubes e federações. Estádios lotados tornaram-se, portanto, muito menos necessários, não apenas pelo advento das novas fontes de receita, mas sobretudo por colocar em risco a própria qualidade do produto que se quer vender: os conflitos entre torcedores e a ameaça que estes podem representar à própria integridade física dos jogadores, tornados valiosos astros milionários na nova economia do futebol (GAFFNEY; MASCARENHAS, 2004, p. 7).

Esse distanciamento como antigo Maracanã pode ser traduzido também pelo termo mais evocado pelos torcedores. Seguindo os padrões internacionais, a modernidade foi percebida com clareza pelos frequentadores, revelando que, apesar das mudanças, o estádio avançou em diversos itens, compreendidos como novos benefícios pelos torcedores.

Agrupamos na categoria "moderno" os termos que traduzissem modernidade, acompanhados de segurança, conforto, tecnologia avançada, acessibilidade.

[...] o torcedor hoje se sente mais respeitado quando vê um estádio preparado pra recebê-lo com conforto e segurança; os serviços, banheiros, bares, estão bem melhores; hoje a fiscalização é mais rígida, não se pode ficar de pé atrapalhando a visão de quem está atrás, não se pode pôr os pés nas cadeiras; estádio melhorou muito $o$ acesso dos torcedores.

Esses termos não são questionados por quem está usufruindo o novo Maracanã. São termos que circularam desde o início da reestruturação, principalmente na mídia e nos órgãos responsáveis pela obra. As imposições da FIFA para os estádios que fossem receber jogos internacionais passaram exatamente por esses quesitos.

É interessante mencionar que o conceito de modernidade é difuso e com múltiplos entendimentos. Feres Junior (2010), apoiado nas ideias de Gumbrecht (1978) ${ }^{4}$, nos mostra que há historicamente três significados básicos para o conceito de "moderno". O primeiro associa-se ao presente, simplesmente em oposição a anterior ou prévio. Outro sentido é atribuído à ideia de um período transitório que se opõe ao conceito de eterno. Nessa pesquisa adotamos um terceiro conceito, definido assim pelo autor:

[...] significado é de 'novo' em oposição a 'velho': nesse caso já se tem o embrião de uma consciência epocal onde moderno define um espaço de experiência presente que se quer distinto do passado. Esse uso geralmente está ligado a um esquema temporal mais ou menos explícito de hierarquização das eras, ou seja, é fortemente valorativo (FERES JUNIOR, 2010, p. 4).

Portanto podemos verificar um núcleo central das representações sobre o novo Maracanã com significados mantidos, o que demonstra que, apesar de novo, de diferente, o Maracanã continua proporcionando momentos de emoção, sendo o espaço aonde se vai para torcer, um espaço espetacular associado ao seu time de futebol.

4 GRUMBRECHT, Hans Ulrich. Modern:modernitat, moderne. Stuttgart: Klett-Cotta, 1978. 
Entretanto, ao lado desses significados, o núcleo central incorporou a modernidade se distanciando do antigo estádio, fato gerador de lembranças, saudades e nostalgia em função de não haver possibilidade de retorno. Significados negativos também foram trazidos talvez pelos torcedores mais saudosistas. Podemos verificar também que o termo "casa", que em 2012 fazia parte do núcleo central,em 2015 não apareceu nas evocações. Possivelmente com a nova arquitetura, as novas dinâmicas e comportamentos os torcedores sintam um distanciamento em relação ao novo espaço. Serão necessárias vivências e experiências que proporcionem aconchego, afetividade, para que com o tempo eles possam se sentir novamente em casa.

Analisando os demais quadrantes observamos que a categoria "títulos" aparecia em 2012 na zona de contraste e hoje está situada na primeira periferia, quadrante que está muito próximo do núcleo. Possivelmente os títulos estejam associados aos momentos marcantes que os torcedores tiveram com seus times no Maracanã. São vitórias simbólicas que ficam marcadas na memória assim como são desejos futuros de que aquele espaço seja o palco de títulos, motivo de alegria para os torcedores.

A zona de contraste é composta pelos termos "grande", "templo" e "futebol", o que significa que, para um subgrupo, o novo Maracanã mantém essas características do antigo estádio. Foram associadas palavras que nos remetem à grandiosidade e ao simbolismo que 0 Maracanã sempre despertou no cenário do futebol. Nesse quadrante verificamos que o lazer não é mais associado ao Maracanã. Aspectos da sociabilidade nesse momento talvez estejam escamoteados pela novidade e modernidade.

Migraram para a segunda periferia a "amizade", que em 2012 estava na zona de contraste, e, junto com "festa" e "torcida",é indício de que aspectos associados à sociabilidade estejam hoje compondo o sistema periférico, mais flexível e com a função de proteger o núcleo central, atualmente estruturadocom outros elementos, que circulam entre os grupos com mais força.

Devemos nos atentar para um termo novo,"elitista", que não foi evocado em 2012 e hoje aparece na zona periférica.

Acho o novo Maracanã frio, talvez pela elitização, por certo distanciamento entre a torcida e o campo; pelo número menor de torcedores; menos gente no estádio, em especial a população de mais baixa renda.

É um termo que merece atenção desde que começaram as discussões sobre a reestruturação. Em 1950, após análises feitas em jornais da época, Tavares e Votre (2015) verificaram que a construção do Maracanã tinha uma clara preocupação de que o espaço atendesse toda a população, que fosse um espaço de lazer inclusive para as classes menos favorecidas, uma vez que se estava investindo dinheiro público na obra.

Apesar de atender a todo tipo de público, Mascarenhas (2012) mostra que sempre houve dentro da monumentalidade do estádio uma clara divisão de classes. A elite e as autoridades permaneciam destacadas na tribuna revestida de mármore, as cadeiras e as arquibancadas para os com poder aquisitivo médio e a geral, que era majoritariamente frequentada pelo "povão" que pagava preços bem reduzidos e assistia em pé a partida com uma visibilidade reduzida.

Com a reestruturação de 2010 muito se questionou sobre os enormes investimentos e sobre quem administraria o estádio ao final da reforma. Com a iniciativa privada gerindo 
o estádio, o objetivo inicial, de 1950, poderia não mais figurar de forma tão clara, pois seria necessário que o estádio gerasse lucro para atender as empresas. A própria disposiçãodos setores do Maracanã mostrava que se teria um atendimento diferenciado para o torcedor com maior poder aquisitivo. $\mathrm{O}$ setor leste e oeste contaria com a melhor visibilidade em relação ao campo, com serviço de buffet, onde se encontrariam os camarotes, portanto, com valores bem superiores ao que o público estava acostumado a pagar para assistir a um jogo de futebol.

Essa questão do valor do ingresso foi discutida na mídia, em artigos acadêmicos e blogs, e após a reabertura também foi motivo de questionamentos por torcidas organizadas. Com isso, possivelmente foram-se construindo esses significados de que o estádio não era mais do povo, era caro, da elite e possivelmente uma parcela de torcedores ficaria impossibilitada de frequentar o novo Maracanã. Embora não tenhamos feito um estudo sobre valores do ingresso e da exclusão social, podemos constatar que esse sentimento começou a circular entre os torcedores que frequentam o estádio, indicativo de que está sendo compartilhado e com 0 tempo pode migrar para o núcleo central.

\section{CONSIDERAÇÕES FINAIS}

A geral, setor mais popular que já não existia desde 2000, a arquibancada de concreto no piso superior e posteriormente com as cadeiras azuis, amarelas e brancas e a grandiosidade que recebia quase duzentos mil torcedores deu lugar a um estádio mais enxuto, onde os torcedores ficam mais próximos ao campo com uma melhor visibilidade. $O$ tremer do concreto deu lugar aos assentos numerados e há regras que tentam manter os torcedores sentados.

As duas rampas monumentais e simbólicas que por muitos anos permitiam a entrada das torcidas juntas foram sendo alteradas e hoje só permitem a entrada de torcedores que compram ingresso para setores específicos. Os demais contam com outras quatro rampas para facilitar o acesso e ter uma melhor evacuação, evitando aglomerações. Ainda há bares e banheiros limpos, telões de última geração, sistema de iluminação e de coleta de água sustentável, possibilidade de compra de ingresso online, entre outras comodidades. O estádio foi reestruturado para ser uma arena multiuso, gerando para os torcedores novas sensações, compatíveis com amodernidade, associadas aitens como conforto e segurança.

Os comportamentos também sofreram alterações em função dessas novas configurações. Aglomerações de torcedores para a entrada foram dissipadas em função dos diferentes portões para cada setor. Os setores não se comunicam mais, impedindo o torcedor de se deslocar no anel interno do estádio. As torcidas organizadas não têm mais espaço para correr nas arquibancadas com suas bandeiras devido a essas segmentações feitascom divisórias. As faixas não têm mais como ser estendidas nos antigos alambrados. A ideia é de não permitir que os torcedores fiquem em pé, o que ainda é bastante difícil nos setores norte e sul, os mais populares,que recebem as torcidas organizadas. Já nos setores leste e oeste os torcedores tendem a permanecer sentados e por muitas vezes reclamam de quem permanece em pé atrapalhando a visão dos demais.

Enfim, são muitas mudanças tanto no campo arquitetônico como no campo das práticas e comportamento dos torcedores. Entretanto, observamos que o Maracanã continua a ser um espaço de festa onde os torcedores cantam, gritam, torcem e se emocionam com seus times. 
A partir dos dois quadros referentes à estrutura das representações sociais sobre 0 estádio do Maracanã, podemos verificar que o núcleo central não foi totalmente alterado em sua composição. Novas categorias foram agregadas, refletindo esse momento de mudança em que a modernidade impõe novos padrões para um estádio mais confortável e mais seguro para todos os atores sociais envolvidos nesse cenário futebolístico.

Ao mesmo tempo em que ele se mostra moderno, alinhado com os novos tempos, nos parece que ainda é um campo fluido, flexível e suscetível às novas adaptações que podem interferir nesse processo de reconstrução de representações. Logo, significados negativos também foram evocados pelos torcedores, nos fornecendo essa ideia de transição.

As lembranças dos momentos positivos vivenciados no antigo estádio, com as histórias afetivas que permitiam aos torcedores se sentirem em casa, ainda não foram possibilitadas no novo Maracanã. Talvez seja necessário um tempo maior para que os torcedores voltem a presenciar vitórias e lances inesquecíveis, histórias de ligações familiares e de amizades que foram construídas no antigo cenário. Esses episódios ainda são vivos nas memórias dos torcedores, fazendo esse trabalho de ligação entre o antigo e o novo Maracanã.

Portanto, a nova arquitetura não interferiu a ponto de alterar o núcleo central das representações sociais sobre o Maracanã, entretanto, jogou os torcedores no campo das contradições. Um estádio moderno, espetacular, grandioso, porém ruim, mal-administrado e feio. O templo Maracanã, espaço dos títulos, do time de coração,em que se acompanha o futebol, o esporte mais popular do Brasil. Espaço da festa, das amizades, do domingo, mas que pode estar se tornando um espaço elitista excluindo uma parcela dos torcedores que o tinham com o espaço da sociabilidade.

\section{REFERÊNCIAS}

ABRIC, Jean Claude. A abordagem estrutural das representações sociais. In: MOREIRA, A. S. P.; OLIVEIRA, D. C. (Org.). Estudos interdisciplinares em representações sociais.Goiânia: $A B, 1998$. p. 27-38.

ALMEIDA, Angela Maria Oliveira; SANTOS, Maria de Fátima de Souza; TRINDADE, Zeide Araújo. Representações e práticas: contribuições teóricas e dificuldades metodológicas. Temas em Psicologia, v. 8, n. 3, p. 257-267, 2000.

BANDEIRA, Gustavo Andrade. Do olímpico à arena: elitização, racismo e heterossexismo no currículo de masculinidade dos torcedores de estádio.2017.342 f. Tese (doutorado) - Universidade Federal do Rio Grande do Sul. Faculdade de Educação. Programa de PósGraduação em Educação, Porto Alegre, 2017.

FERES JUNIOR, João. Introdução a uma crítica da modernidade como conceito sociológico. Mediações, v. 15, n.2, p. 28-41, jul./dez. 2010.

GAFFNEY, Christopher; MASCARENHAS, Gilmar. O estádio de futebol como espaço disciplinar. In: SEMINÁRIO INTERNACIONAL MICHEL FOUCAULT, 2004, Florianópolis. Anais...

Florianópolis, 2004. Disponível em: <https://pt.scribd.com/document/154718749/GAFFNEY-CEstadio-como-espaco-disciplinar>. Acesso em: 10 maio 2018. 
MASCARENHAS, Gilmar. O futebol no Brasil: reflexões sobre paisagem e identidade através dos estádios. In: BARTHE-DELOIZY, F.; SERPA, A.(Orgs). Visões do Brasil: estudos culturais em Geografia. Salvador: EDUFBA; Edições L'Harmattan, 2012. p. 67-85.

MASCARENHAS, Gilmar. Um jogo decisivo, mas que não termina: a disputa pelo sentido da cidade nos estádios de futebol. Cidades, v.10, n. 17, p. 142-170, 2013.

MELLO, Eduardo de Castro. O estádio de futebol e sua percepção inovadora. Revista USP, $n$. 99, p. 153-158, set./nov. 2013.

OLIVEIRA, Denise et al. Análise de evocações livres: uma técnica de análise estrutural das representações sociais. In: MOREIRA, A. S. P. et al.(Eds.).Perspectivas teóricometodológicas em representações sociais. João Pessoa: UFPB, 2005. p. 573-603.

ROUQUETTE,Michel-Louis. Representações e práticas sociais: alguns elementos teóricos. In: MOREIRA, A. S. P.; OLIVEIRA, D. C. (Org.).Estudos interdisciplinares em representações sociais.Goiânia: AB, 1998. p. 39-46.

TAVARES, Ana Beatriz Correia; VOTRE, Sebastião Josué. Estádio do Maracanã: dos alicerces ao colosso do Derby. Revista Brasileira de Ciências do Esporte,v.37, n. 3, p.258-264, ago. 2015.

TAVARES, Ana Beatriz Correia; VOTRE, Sebastião Josué. Estádio do Maracanã de 1950-2010 na memória dos torcedores. Movimento, v.20, n.3, p. 1017-1038, jul./set. 2014.

TUAN, Yi-Fu. Espaço e lugar: a perspectiva da experiência. São Paulo: DIFEL, 1983.

VOTRE, Sebastião Josué; ALVES, Ana Paula; MELILLO, Carlos Eduardo. Abordagem radical das representações sociais. Corpus et sciencia, v.6, n.2, p. 11-18, ago. 2010.

WACHELKE, João; WOLTER, Rafael. Critérios de Construção e Relato da Análise Prototípica para Representações Sociais.Psicologia: Teoria e Pesquisa,v.27, n. 4, p. 521-526, out./dez. 2011. 